\title{
Estado atual da sistemática dos peixes de água doce da América do Sul
}

\author{
James E. Böhlke 1 \\ Stanley H. Weitzman ${ }^{2}$ \\ Naercio A. Menezes ${ }^{3}$
}

\begin{abstract}
Resumo
A fauna sul-americana de peixes de água doce, comparada com a do resto do mundo, é pouco conhecida. Há necessidade de coletas imediatas em muitas regiões, antes que os peixes se tornem raros ou se extingam. A fase descritiva da fauna de peixes de água doce da América do Sul desenvolveu-se em três períodos históricos. De 1750 até aproximadamente 1866 , boa parte dos grandes exemplares de interesse comercial foi descrita por zoólogos europeus. De 1866 a 1930, caracterizou-se por descriçôes de espécies de grande e pequeno porte, por ictiólogos tanto europeus como norte-americanos. De 1930 ao presente, foi, em parte, um período em que surgiram descrições adicionais na América do Norte, Europa e América do Sul. De 30 a $40 \%$ da fauna de peixes de água doce da América do Sul estão por ser descritos. Em termos de descrição e inventariação, o conhecimento desta fauna é comparável ao da fauna de peixes de água doce dos Estados Unidos e Canadá há cerca de 100 anos. Existem atualmente 2.500 a 3.000 espécies conhecidas de peixes de água doce na América do Sul e o número final pode chegar a 5.000 . A não disponibilidade de bibliografia antiga sobre peixes, de exemplares de museu para comparações adequadas, e a falta de trabalhos faunísticos para a maior parte das áreas, săo fatores que dificultam e até mesmo impossibilitam ictiólogos e biólogos de pesca no desempenno satisfatório de suas profissões na América do Sul. Muitas espécies descritas antes de 1870, precisam ser estudadas e redescritas. A maior parte dos grupos de peixes de água doce sul-americanos necessita revisões taxonômicas modernas.
\end{abstract}

\section{INTRODUÇÃO}

Em comparação com outros grupos de vertebrados, pouco se conhece sobre sistemática, evolução, ecologia, fisiologia, etologia, morfologia e genética de peixes. As razões são muitas. A principal talvez seja o elevado número de espécies (pouco mais de 20.000), que equivale aproximadamente ao número de espécies de todos os demais vertebrados. $\mathrm{O}$ ambiente em que os peixes vivem torna sua captura, observação e a determinação de seus parâmetros biológicos mais difícil, em compa. ração com a maioria dos outros vertebrados.

Entre os peixes de água doce, os menos conhecidos são os do sudeste da Ásia e os da América do Sul. Apenas sob o ponto de vista da catalogação, o estágio de conhecimento atual da fauna de peixes de água doce da América do Sul equivale ao da fauna dos Estados Unidos há cerca de 100 anos. Isto se deve a vários motivos. A fauna de peixes da América do Sul é muito mais rica e complexa do que a norte-americana, possuindo cerca de 60 famílias (42 para os Estados Unidos e Canadá) e mais de 2.500 espécies (cerca de 620 para os Estados Unidos e Canadá). O tamanho dos sistemas fluviais (o rio Amazonas sozinho é responsável por cerca de $20 \%$ de toda a água doce descarregada nos oceanos pelos rios e riachos de todo $\mathrm{c}$ mundo) e a dificuldade de acesso a muitos tributários do Amazonas e do Orinoco, aliados ao elevado custo das expedições para a coleta de peixes nestas áreas, são fatores que limitam o conhecimento dos peixes de água doce neotropicais. A América do Sul isolou-se de outras áreas continentais há cerca de 70 milhões de anos. A grande diversidade de ambientes ecológicos existentes permitiu uma irradiação evolutiva provavelmente igualada ou ultrapassada apenas pelos peixes marinhos da região Indo-Pacífica. Nos Estados Unidos e Canadá, o grupo predominante de peixes de água doce, Ostariophysi, é representado por 3 famílias e cerca de 50 gêneros. Na América do Sul o mesmo grupo é representado no mínimo por 29 famílias e talvez 500 gêneros. Contudo, durante os últimos

(1) - Academy of Natural Sciences, Philadelphia, Penns ylvania, Estados Unidos.

(2) - National Museum of Natural History, Smithsonian Institution, Washington, D.C., Estados Unidos.

( 3 ) - Museu de Zoologia da Universidade de São Paulo, São Paulo. 
100 anos, o total de homens/horas dedicados ao estudo dos peixes de água doce da América do Sul foi muito menor do que o gasto no estudo dos peixes de água doce dos Estados Unidos e Canadá. Houve e continua havendo poucos recursos para uma exploração adequada conjunta e em larga escala dos peixes de água doce da América do Sul.

O conhecimento de qualquer fauna não pode progredir efetivamente sem pesquisas iniciais adequadas. Atualmente o levantamento ou cataıogaçao da fauna de peixes de água doce da America do Sul é tão incompleto, que o progresso nos estudos da ecologia e da biologia pesqueira se torna grandemente limitado. $\mathrm{Em}$ alguns casos, os nomes científicos, mesmo dos principais peixes de interesse comercial da Bacia Amazônica, são desconhecidos ou duvidosos; as listas de tais peixes trazem muitas vezes nomes científicos errôneos, com interrogação, ou até omitidos. Numa relaçảo dos principais peixes consumidos em Manaus, uma das mais importantes cidades da Amazônia, por exemplo, 8 dos 20 nomes científicos dos peixes comerciais mais comuns são duvidosos (Lowe-Mc Connell, 1975:74, tabela 3.2). Em nossa opinião, muitos outros nomes poderiam também ser considerados duvidosos. Um dos motivos da falta de conhecimento desses peixes é o pequeno número de revisões dos vários gêneros aos quais pertencem. Identificações seguras são impossíveis sem tais revisões.

Em outras regiões da América do Sul a situação não é nada animadora. Na Venezuela, sudeste da Colômbia e partes da região costeira leste do Brasil, a catalogação é, talvez, ainda mais incompleta.

A atual falta de conhecimentos não seria tão constrangedora se as amostragens da fauna de peixes de água doce se mantivessem em pé de igualdade (ou melhor, à frente) do desenvolvimento econômico. Este acarreta como conseqüência principal a alteração do meio ambiente, causando muitas vezes a extinção de algumas espécies. As barragens, a destruição de florestas, o assoreamento, e a introdução de espéciles de uma bacia hidrográfica em outra, são alguns dos mais sérios problemas que alteram os ecossistemas naturais. Os pes- ticidas e a poluição industrial também podem causar alterações irreversiveis na fauna, por extinção e desequilíbrio ecológico. A industrialização e as alterações causadas pela utilização do solo para a agricultura se processam rapidamente em muitas partes da América do Sul. Muitas espécies já podem ter desaparecido; provavelmente muitas serão destruídas antes que possam ser feitos levantamentos da flora e da fauna aquáticas. Referindo-se a este tipo de problema, Cohen (1970) diz:

In view of the high percentage of fishes (number of species) found in fresh water and man's increasing modification of this environment throughout the world, it is vital that research be cirastically increased on the basic systematics of freshwater fishes while this is still possible.

Acreditamos firmemente que as implicações desta afirmação devem ser uma preocupaçăo constante da comunidade internacional.

Existem muitos outros motivos para se acelerar o ritmo do estudo dos peixes de água doce sul-americanos: (1) Econômico - A pesca em água doce, embora sendo relativamente pequena na América do Sul, e quase todo o pescado consumido localmente, é fonte de renda importante para milhares de pessoas; (2) Saúde - Os peixes de água doce constituem uma importante fonte de proteína para as populações que vivem em áreas afastadas do litoral e onde a criação de gado é difícil; (3) Científico - A fauna extremamente complexa de peixes de água doce da América do Sul é,do ponto de vista evolutivo, um dos grandes produtos do mundo biológico. Deixar de lado a oportunidade de estudar mesmo uma pequena parte deste sistema complexo, seria uma perda lastimável para o acervo de conhecimentos da humanidade; (4) Estético - $O$ conhecimento e a compreensão de ecossistemas complexos trazem consigo alguns valores estéticos para a humanidade. $\mathrm{Na}$ fauna de peixes de água doce da América do Sul, vamos encontrar alguns dos mais belos peixes do mundo, muitos dos quais constituem fonte educacional e estética para milhões de aquaristas, especialmente na Europa e América do Norte. Quanto mais conhecermos esses peixes, mais capacitados estaremos para preservar esta herança para futuras gerações. 


\section{AGRADECIMENTOS}

Este artigo é em parte uma ampliação de algumas secções do relatório preparado para a American Society of Ichthyologists and Herpetologists, Advisory Committee, por James E. Böhlke (veja apêndice IV em Lachner et al., 1976) .

Expressamos nossos melhores agradecimentos a William A. Gosline, que nos forneceu a maior parte das informações históricas. Agradecemos também a William G. Saul, Marilyn Weitzman, Sara H. Fink e William L. Fink, pelo auxílio na preparação e edição deste trabalho. O auxílio financeiro foi recebido da Smithsonian Amazonian Ecosystem Rearch Program, sob a direção de Clifford Evans.

\section{Histórico SUCINTO DA DESCOBERTA E DESCRIÇÃO DOS PEIXES DE ÁGUA DOCE DA AMÉRICA DO SUL}

A história da descoberta e descrição dos peixes de água doce da América do Sul pode ser dividida em três períodos. As primeiras descobertas e a descrição dos peixes maiores $\epsilon$ mais comuns vão aproximadamente da metade do século XVII até 1866 . O período de 1866 a 1930 caracterizou-se pela descoberta e descrição de um grande número de espécies de todos os tamanhos, capturadas durante as diversas expedições realizadas com o objetivo principal de coletar peixes. De 1931 ao presente novas descrições foram feitas, mas, mais importante durante este período, foi a tentativa de avaliação do que fora feito nos dois períodos anteriores, à luz dos novos conhecimentos sobre "sistemática biológica" surgidos nos últimos 50 anos. Cada um desses três períodos é caracterizado por diferenças nos tipos de peixes descobertos e descritos, por diferenças nos princípios biológicos e filosóficos que nortearam o trabalho descritivo e também por diferenças na exatidão, profundidade $e$, conseqüentemente, utilidade das descrições.

O primeiro período caracterizou-se principalmente pela publicação (quase que inteiramente na Europa) das descrições dos peixes de grande porte utilizados como alimento, mui- tas vezes obtidos nos mercados das diversas cidades e povoados da América do Sul. Na maioria dos casos, as descrições são extremamente sucintas, parcamente ilustradas em comparação com os padrões atuais e têm como objetivo principal apenas possibilitar a diferenciação entre os peixes recém-descobertos e os outros peixes já conhecidos de outras partes do mundo. Em virtude do drástico aumento do número de espécies conhecidas, estas primeiras descrições tornaram-se obsoletas e inadequadas para o reconhecimento dos peixes sul-americanos, geralmente muito semelhantes entre si; em conseqüência, muitas vezes é difícil determinar a que espécie o autor se refere, sem recorrer ao exemplar que ele examinou, e que, na maioria dos casos, não mais existem. As descrições iniciais foram feitas sem levar em conta o processo evolutivo, a especiação e a variação geográfica das espécies, como conhecemos atualmente. Na maioria dos casos, os peixes eram descritos sem diedos precisos sobre a localidade de coleta, dificultando ainda mais o trabalho de identificação da espécie. Esses peixes, em sua grande maioria, nunca foram redescritos de acordo com os métodos atuais de descrição e comparação.

Os primeiros peixes de água doce sulamericanos foram descritos em 1648, quando dois médicos, Wilhelm Piso e Georg Marcgrave publicaram um tratado de medicina e de história natural do Brasil, editado por Johannes de Laet. Marcgrave (1648) contribuiu com uma secção em 8 partes separada e paginada, "Historia rerum naturalium Brasiliae"; a quarta parte inclui cerca de 100 espécies de peixes, dos quais quase a metade de água doce. As descrições foram muito bem feitas, se comparadas com as demais daquela época em todo o mundo; na verdade, a maioria pode ser considerada avançada para a época (veja-se Whitehead, 1973, para maiores informações sobre a obra de Marcgrave). Quase nada de novo apareceú no século seguinte sobre os peixes de água doce sul-americanos. Apenas 10 espécies de peixes de água doce da América do Sul foram descritos na décima edição do "Systema Naturae" de Linnaeus (1757), obra que pretendeu incluir todos os organismos conhecidos na época. 
No final do século XVIII, o estudo dos peixes de água doce da América do Sul começou a progredir. Mark Elieser Bloch, em sua "Naturgeschichte der ausländischen Fische" (1785-1795), descreveu e ilustrou em cores 21 espécies de Siluriformes e Characoidei sulamericanos. De 1783 a 1792, durante as expediçōes de Alexandre Rodrigues Ferreira, foram feitas grandes coleçôes na Amazônia brasileira e Mato Grosso e preparadas várias ilustrações de peixes sul-americanos, algumas das quais apenas recentemente publicadas (Ferreira, 1971, 1972). As coleçöes de A. R. Ferreira e muitas das ilustrações feitas, foram enviadas a Portugal, mas devido à invasão de Lisboa durante as guerras napoleônicas, as coleções, ou pelo menos parte delas, foram confiscadas e levadas para o "Jardin des Plan; tes", em Paris.

No ano de 1817, dois alemães, Johann Baptist von Spix e Carl Friedrich von Martius, e um grupo de outros cientistas, chegaram ao Brasil. Faziam parte do séquito da Arquiduquesa Leopoldina Carolina Josefa da Austria, vinda ao Brasil para casar-se com o príncipe herdeiro, Dom Pedro de Alcântara. Com o apoio da coroa, Spix e Martius viajaram pelo interior do Brasil e no rio Amazonas por cerca de 2 anos e 11 meses, retornando à Europa em 1820. Lá, Spix desenhou uma série de pranchas coloridas dos peixes coletados, mas morreu antes de completar o texto. Louis Agassiz, então com 21 anos, deu continuidade à obra $e$ escreveu grande parte do texto como sua tese de doutoramento, na Universidade de Munique. Este trabalho foi publicado juntamente com as pranchas de Spix em 1829-1831 e projetou Agassiz como biologista. O trabalho inclui 52 espécies de peixes de água doce da América do Sul.

Entre os acompanhantes da comitiva da arquiduquesa também se encontrava Johann Natterer, de Viena, que permaneceu no Brasil por um período de 18 anos, coletando uma grande variedade de objetos de história natural, nos rios Amazonas, Negro e Paraguai e no sudeste do Brasil. Suas coleções, enviadas ao Museu de Viena, serviram de base a uma série de descrições de peixes de água doce sul-americanos publicados por Jakob Heckel e Rudolf Kner. Heckel (1840) descreveu cerca de um quarto das espécies atualmente conhecidas de ciclídeos da América do Sul, baseado nas coleções de Natterer. Kner (1853 a 1859) publicou uma série de trabalhos sobre Siluriformes e Characoidei, baseado nessas mesmas coleções.

De 1830 a 1850 , vários naturalistas e colecionadores viajaram pela América do Sul. Robert Herman Schomburgk explorou a Guiana Inglesa (atual Guyana) e os rios Negro, Branco e Orinoco, de 1835 a 1839 ; de 1840 a 1844 , repetiu a viagem em companhia de seu irmão Richard Schomburgk. Robert Schomburgk recebeu apoio material do governo britânico e Richard Schomburgk do rei da Prússia, graças à influência de Alexandre von Humboldt. O trabalho de Robert Schomburgk, sobre os peixes coletados, foi editado e publicado por Sir William Jardine, como parte da "Naturalist's Library", em dois volumes intitulados "Fishes of Guiana" (Schomburgk, 1841b e 1843). O trabalho inclui 83 espécies; cerca da metade provavelmente coletada no rio Negro, no Brasil. Alguns dos desenhos são aparentemente compostos, pois em alguns casos foram feitos esboços preliminares a partir de exemplares recém coletados, e as cores acrescentadas a partir de outros exemplares (não necessariamente da mesma espécie) coletados posteriormente (veja-se Eigenmann, 1912, para maiores informações sobre o assunto). Este fato tem causado sérios problemas para o íctiólogo sistemata. A primeira viagem de Robert Schomburgk é decsrita em suas "Reisen im British Guiana un am Orinoko während den Jahren 1835-1839". As viagens de Richard Schomburgk foram publicadas em "Reisen in British Guian in den Jahren $1840-44$... " e suas coleçōes serviram de base para o trabalho "Horae Ichthyologicae" de Johannes Müller e Franz Herman Troschol (1845-1849) .

Ainda entre os naturalistas que viajaram pela América do Sul durante este período, vamos encontrar Francis de Castelnau e Charles Darwin. Castelnau percorreu a América do Sul, especialmente a Bacia Amazônica, de 1843 a 1847 , e fez um relato (1855) dos peixes de água doce coletados. O trabalho de Castelnau é bastante impreciso, tendo muitas das espécies ali descritas caído em sinonímia. Darwin 
coletou pouquíssimos peixes de água doce da Argentina, descritos por Leonard Jenyns (1842).

Durante o período inicial do século XIX, - Barão de Cuvier solicitou coleções de peixes de exploradores de todo o mundo. As coleções provenientes da América do Sul, inclusive as de Alexandre Rodrigues Ferreira acima mencionadas, serviram de base para diversos trabalhos, contendo descrições de novos peixes de água doce. Em Paris, após 1832, Achille Valenciannes continuou o trabalho inicrado por Georges Cuvier, intitulado "Histoire Naturelle des Poissons" (1828-1849). Pretendia incluir a maioria das espécies de peixes de água doce da América do Sul até então conhecidas, bem como todos os peixes do mundo. A obra nunca foi completada, mas 22 volumes foram publicados. Com as novas formas descritas, o número de espécies conhecidas de peixes de água doce da América do Sul elevou-se a 331, com exceção dos ciclideos. O trabalho baseou-se em sua maior parte nas grandes coleções que formam o acervo atual do "Muséum National D'Histoire Naturelle de Paris" (então conhecido como "Jardin des Plantes").

$\mathrm{Na}$ segunda metade do século XIX, a teoria da evolução, proposta por Darwin, começou a exercer uma profunda influência nos estudos de história natural. Embora suas implicações pouco tenham influenciado alguns ictiólogos (Agassiz, por exemplo, nunca aceitou a teoria), houve uma mudança. Começou a haver um interesse crescente em história natural. Os ictiólogos, em particular, começaram a perceber que havia um número elevado de pequenas espécies a serem descritas na América do Sul. Antes deste período, excetuando-se talvez os trabalhos de Cuvier e Agassiz, a maioria dos trabalhos descritivos sobre peixes sul-americanos poderia ser considerada como curiosidade de história natural. Subseqüentemente à proposição da teoria da evolução, a história natural e a sistemática biológica começaram a ser encaradas como uma forma de testar a teoria. Tal fato levou muitos ictiólogos a olhar mais atentamente para os temăs de seus estudos e a se interessar não somente pelos grandes peixes comestíveis de interesse econômico.
O segundo período de descobertas ictiológicas da América do Sul começou no período de 1865-1866, quando Louis Agassiz, entăo na Universidade de Harvard, liderou a Expedição Thayer (apoiada financeiramente por Nathaniel Thayer) às partes média e inferior da Bacia Amazônia e ao leste do Brasil (veja-se em Agassiz \& Agassiz, 1868, o histórico desta expedição). Esta foi a primeira expedição com o objetivo principal de coletar peixes e determinou novos rumos para o estudo dos peixes sulamericanos. Um novo centro de estudo desses peixes surgiu na América do Norte; até então o estudo da ictiologia tinha como centro principal a Europa. Agassiz foi o primeiro investigador a reconhecer de modo cabal a imensa variedade de espécies de pequeno porte existente na Bacia Amazônica. Isto influenciou fortemente sua metodologia em relação às coletas. Os exploradores que o antecederam, com a notável exceção de Natterer, limitaram suas coletas às espécies de grande porte, utilizadas como alimento (sobre a influência de Agassiz na ictiologia da América do Sul, consulte-se Myers, 1943). Agassiz contribuiu também para a mudança de curso da ictiologia da América do Sul, quando persuadiu Franz Steindachner, do Museu de Viena, a dirigir-se a Harvard, em 1871, por dois anos e meio, a fim de trabalhar os peixes da coleção Thayer. Steindachner acompanhou a Expedição Hassler ao sul do Brasil, obteve material para o Museu de Viena e fez contatos locais com algumas pessoas que mais tarde lhe enviaram coleções. Quando do seu regresso a Viena, Steindachner levou duplicatas da maior parte da coleção Thayer. A partir desta data, até 1917, publicou uma longa série de trabalhos, descrevendo novas espécies de peixes sul-americanos e assinalando muitas outras espécies em diversas localidades (Duncker, 1914, publicou um indice de vários trabalhos de Steindachner). Felizmente, mais do que qualquer outro ictiólogo de sua época, Steindachner pareceu reconhecer a importância de descrições as mais completas e acuradas possíveis. Sua experiência no estudo das enormes coleções Agassiz-Thayer e sua própria experiên. cia de coletas na América do Sul, sem dúvida fizeram-no compreender a complexidade da fauna ictiológica neotropical e a necessi- 
dade de descrições precisas e completas. As litogravuras de Edward Konopicky, que acompannam muitas das descriçōes de Steindachner, constıtuiram uma inovação importante pelo fato de terem acrescentado um novo elemento as ilustraçöes de história natural: a exatidāo. O sudeste do Brasil (Steindachner, $1874,1875,1876$ ) e a bacia do rio Magdalena na Colombia (Steindachner, 1879) foram as duas regıoes mais intensamente cobertas. Os trabaınos de Steindachner tratam, porem, dos peixes de quase todas as principals áreas da America do Sul. Pode-se considerar extremamente auspicioso o tato de Steindachner ter tido a capacıaade de descrever táo bem uma parte consıderável dessa fauna.

No catálogo que pretendia incluir todos os peixes connecıaos de sua época, Albert Günther do Museu Britänico, pubiicou entre 1859 e 1870 descriçōes sumárias dos peixes de água doce sul-americanos. Neste trabalho, Günther descreveu como novas todas as espécies do Museu Britänico que foi incapaz de identificar por meı de descriçōes previas. Embora Günther tivesse um conhecimento muito grande aos peixes de todo o mundo e uma notável intulçao das relaçoes entre os diversos grupos, suas descriçōes são muitas vezes tão sumárias e cripticas que dificultam o trabalho de identificaçao das espécies; quase todas são desprovidas de ilustrações.

Entre 1887 e 1911, Albert Boulenger, também do Museu Britânico, publicou uma pequena série de trabalhos faunisticos sobre peixes de água doce sul- americanos, descrevendo várias espécies novas.

Em 1888, Carl Eigenmann, da Universidade de Indiana, iniciou sua ambiciosa e produtiva carreira, que iria durar cerca de 40 anos, estudando.e coletando peixes de água doce da América do Sul (a lista dos trabalhos publicados por Eigenmann até 1927 pode ser encontrada em Payne, 1928). Entre todos os que estudaram peixes sul-americanos é, sem dúvida, o mais importante. Sob sua orientação, e muitas vezes com sua participação, foram feitas as mais importantes coleções de peixes da América do Sul, bem como os estudos faunísticos e as revisões mais completas dos diversos grupos de peixes de água doce sul-americanos. Sua primeira grande contribuição, a revisão dos bagres sul-americanos, foi publicada em colaboração com a esposa, Rosa Smith Eigenmann, em 1890, e se baseou principalmente nas coleções Thayer. O trabalho inclui 467 espécies; até o presente năo se fez nenhuma outra revisão geral dos bagres da América do Sul. Em 1891 publicou seu primeiro catálogo de peixes de água doce da América do Sul, relacionando 1.135 espécies.

Em 1908 Eigenmann fez a sua primeira viagem à América do Sul. Passou a maior parte do ano coletando na Guyana (então Guiana Ingiesa). As grandes coleçôes resultantes constituiram a base principal de sua volumosa monografia faunística "Freshwater Fishes of British Guiana" (1912). Publicou também (1910) o "Catalogue of the Fresh-water Fishes of Tropical and Temperate South America" e relacionou 1917 espécies (782 a mais que as de seu catálogo de 1891). Estas listas incluiam também os peixes de água doce da América Central. Sua monografia sobre os peixes de água doce da Patagônia foi publicada em 1909. Sob sua direção ou influência, importantes coleções foram feitas por John Haseman no Brasil (especialmente no sul do Brasil) e por Carl Ternetz no Amazonas e um de seus afluentes, o Tocantins, e também em trechos dos rios Negro e Orinoco. Eigenmann e vários de seus colaboradores fizerem importantes coleções no Chile, Peru, Colômbia e Equador. Foram publicados volumosos relatórios faunísticos, feitos com base nestas coleções, como por exemplo, "The Fresh-water Fishes of Northwestern South America, Part I (Eigenmann, 1922) e "The Fresh Water Fishes of Chile" (Eigenmann, 1927). Há ainda partes consideráveis destas coleçōes que nunca foram trabalhadas. Tais coleçōes, entretanto, devem ser estudadas em conjunto com o material recente de áreas geográficas adjacentes. A coleção de Haseman foi estudada, pelo menos parcialmente, por Eigenmann e seus colaboradores. Publicaram uma série relativamente grande de pequenos trabalhos. Atualmente a maior parte desta coleção encontra-se depositada no Field Museum of Natural History, Chicago, e continua pouco estudada. As coleções de Ternetz, atualmente depositadas quase totalmente na California Academy of Sciences, San Francisco, California, permanecem prati- 
camente intactas. Tendo por base as coleçōes acima, Eigenmann e seus discípulos publicaram diversos trabalhos curtos, a maioria com descriçōes de espécies novas provenientes de várias bacias hidrográficas da América do Sul. Eigenmann (1917-1929) também publicou revisões de alguns grupos de bagres (Trichomycteridae e Doradidae), de certcs caracideos (Serrasalminae) e uma grande monografia em cinco partes sobre Tetragonopterinae e outros grupos de caracídeos; a última parte foi publicada após sua morte, tendo George S. Myers como co-autor. A última contribuição de Eigenmann consta de um volumoso relato faunistico, "The Fishes of Western South America" (1942), publicada em co-autoria com William Ray Allen e tendo como base as coleções feitas por Allen em 1920 no leste do Peru. Um alunc de Eigenmann, Max Ellis, publicou uma monografia sobre gimnotídeos (The Gymnotid Eels of Tropical America, 1913), grupo de peixes de água doce que possui órgãos elétricos, atualmente de grande interesse em estudos de fisiologia, mas cuja sistemática permanece num estado arcaico, dificultando estudos modernos de ecologia e eletrofisiologia.

No periodo compreendido aproximadamente entre 1904 e 1914, C. Tate Regan, do Museu Britânico, escreveu uma série de curtos trabalhos faunisticos, mas também importantes revisões de ciclídeos, pecilídeos e loricarídeos neotropicais. Ainda durante esta época, no Rio de Janeiro, Alípio de Miranda Ribeiro publicou uma importante revisão dos bagres brasileiros (1911) e numerosos outros trabalhos sobre caracídeos e ciclídeos brasileiros.

Do início do século $X X$ até aproximadamente 1950, Henry W. Fowler, da Academy of Natural Sciences, Filadelfia, publicou uma série de trabalhos faunisticos sobre peixes de água doce da América do Sul. Seu trabalho mais útil, "Os peixes de água doce do Brasil". foi publicado em quatro partes, de 1948 a 1954. A obra de Fowler apresenta o mesmo estilo dos estudos pré-1930 e está longe dos padrōes estabelecidos por Steindachner e Eigenmann.

Após a morte de Eigenmann em 1927, o progresso no campo da ictiologia sistemática na América do Norte trouxe como conseqüência uma mudança na abordagem do trabalho descritivo e comparativo e exigiu um grau mui- to maior de exatidăo em relação ao que havia sido publicado anteriormente. A maoir parte desses trabalhos, concernente à avaliação dos problemas de relaçōes entre espécies e à dispersāo geográfica dos peixes de água doce da América do Norte, bem como a rápida evolução dos conceitos de biologia sistemática, tiveram uma influência decisiva na mudança de atitude dos ictiólogos interessados nos aspectos descritivos dos peixes sul-americanos. Entretanto, a falta de coleções adequadas de peixes de água doce sul-americanos impediu a realização dos tipos de estudos que vinham sendo feitos com peixes de água doce na América do Norte. Muitos dos ictiólogos que eventualmente poderiam se interessar por peixes sul-americanos voltaram-se para os peixes norte-americanos. Assim, o terceiro período da história da ictiologia na América do Sul caracterizou-se por uma mistura de tendências. Alguns ictiólogos têm tentado fazer revisões de grupos de peixes afins, usando novos conceitos, ou têm tentado atualizar o que se conhece dos peixes sulamericanos. Outros têm continuado a descrever espécies seguindo a tradição de Eigenmann.

George S. Myers, da Stanford University, aluno e colega de Eigenmann, publicou numerosos trabalhos sobre peixes de água doce sul-americanos, de 1920 ao presente (os trabalhos publicados por Myers de 1920 a 1969 foram listados por Anônimo, 1970). Vários discipulos de Myers, entre os quais William A. Gosline, James E. Böhlke, Stanley H. Weitzman e Tyson R. Roberts, continuaram publicando alguns trabalhos faunísticos e um certo número de revisōes e estudos filogenéticos, especialmente sobre Characoidei e bagres. Este trabalho continua até hoje.

Leonard P. Schultz, da Smithsonian Institution, coletou peixes na Bacia de Maracaibo, Venezuela, em 1942, e publicou três importantes trabalhos faunísticos baseados em suas coleçōes: sobre Siluriformes (1944a), sobre Characoidei (1944b) e sobre Gymnotoidei e peixes pertencentes a outros grupos (1949).

Desde 1940 George Dahl tem publicado artigos sobre os peixes da Colômbia e sua maior contribuiçăo consiste em um trabalho que engloba os peixes do nordeste da Colômbia (1971) . 
Augustín Fernandez Yépez, a partir de 1948, publicou um certo número de trabalhos contendo a descrição de peixes da Venezuela. De 1940 a 1950 , Paulo de Miranda Ribeiro, e a partir da década de 1940 até 1977 Haroldo Travassos, ambos do Museu Nacional do Rio de Janeiro, publicaram uma série de trabalhos, principaımente sobre peixes de água doce do suceste do Brasil. Heraldo A. Britski, do Museu de Zoologia da Universidade de Sảo Paulo, continua trabainando com os peixes do sudeste do Brasil, especialmente com bagres, enquanto Naercio A. Menezes, da mesma instituıçāo, esta presentemente fazendo a revisāo de alguns grupos de Characoidei. Na Argentina, Raul A. Ringuelet et al. recentemente (1967) publicaram um importante trabalho faunistico sobre os peixes daquele pais. M. boeseman de Leiaen e H. Nijssen e I. Isbrücker de Amsterdã, têm estudado exaustivamente os bagres (Ioricarideos e caiıctideos) principaimente do Suriname. Os peixes oviparos da família Cyprinodontidae da América do Sul estâo sendo estudados por Jamie Thomerson, dos Estados Unidos e Raúl Vaz-Ferreira do Uruguai. Francisco Mago Leccia, da Venezuela, trabalha atualmente com peixes de água doce da Venezuela, especialmente bagres e Gymnotoidei; em 1975 publicou uma lista de peixes da Venezuela. P. Cala está estudando os peixes de água doce da Colômbia.

Desde 1959, Jacques Géry, da França, tem publicado muitos trabalhos sobre Characoidei da América do Sul; iniciou igualmente uma série sobre os Characoidei das Guianas (veja-se Géry, 1972a) .

M. P. de Godoy (1975) publicou recentemente um longo estudo sobre os Characoidei da bacia do rio Mogi-Guaçú, no Estado de São Paulo.

De 1900 até o presente, um grande número de pequenos peixes de água doce têm sido exportados por aquaristas para a Europa e Estados Unidos. Nestas remessas muitas vezes estâo incluídas novas espécies e ictiólogosaquaristas, especialmente na Alemanha, como por exemplo Ernst Ahl e Hermann Meiken, têm descrito algumas destas espécies na literatura aquariófila e também na zoológica.
AVALIAÇÃo DO ESTADo ATUAL DA SISTEMática DOS PEIXES DE ÁGUA DOCE DA AMÉRICA DO SUL

A sistemática biológica tem dois objetivos principais: (1) descobrir organismos desconhecidos, aplicando-lhes nomes científicos, uma função primordialmente descritiva e (2) apresentar e testar hipóteses sobre aspectos evolutivos e relaçōes filogenéticas entre organismos conhecidos, com a utilização de certos caracteres, principalmente morfológicos. Uma das conseqüências desses objetivos é uma ciassificação. Os resultados da pesquisa sistemática podem ser utilizados em outras áreas da biologia, tais como zoogeografia, genética, ecologia, comportamento, fisiologia e epidemiologia, as quais, por sua vez, podem fornecer subsídios para testar hipóteses filogenéticas. No caso dos peixes, todas estas modalidades de pesquisa formam, em conjunto, um dos dois principais componentes dos estudos relacionados à pesca (o outro é o econômico). Sem o conhecimento da evolução, proporcionado pelos estudos de sistemática, as outras pesquisas teriam um valor apenas relativo.

Uma vez que tanto o objetivo (1) como o (2) acima são necessários para o estabelecimento de hipóteses sistemáticas sobre evolução e relaçōes dos peixes, qual tem sido o tratamento dispensado aos peixes de água doce da América do Sul com relação a este aspecto?

\section{ICTIOLOGIA DESCRITIVA}

$\mathrm{O}$ aspecto descritivo deve ser considerado em primeiro lugar, porque dele depende o segundo, que representa o aspecto construtivo dos estudos evolutivos. $\mathrm{O}$ aspecto descritivo dos peixes de água doce sul-americanos pode ser discutido tentando-se responder a duas perguntas: (a) até que ponto o inventário feito é completo? e (b) qual a qualidade do trabalho descritivo?

É praticamente impossível calcular o volume de trabalho descritivo a ser feito quanto aos peixes de água doce sul-americanos. Uma coisa é certa: é uma tarefa gigantesca. Talvez um cálculo subjetivo possa ser feito, comparando-se o que foi feito em termos de exploração ictiológica nos Estados Unidos e Canadá com o que foi feito na América do Sul. A fauna 
de peixes de água doce da América do Norte ao norte do México é muito menos complexa do que a da América do Sul. Nos Estados Unidos, todos os principais rios, e uma percentagem elevada de seus tributários, foram explorados e amostrados quase completamente. Mesmo assim, as espécies novas não descritas, mas facilmente detectadas, montam a aproximadamente $8 \%$ do total das 621 conhecidas (Jenkins, 1976:643). O número de espécies a serem descobertas, além das relacionadas por Jenkins, é provavelmente mínimo, não chegando talvez, a 1 ou $2 \%$ do total. Na América do Sul, a percentagem de espécies (e gêneros) desconhecidas é, ao que tudo indica, muito mais alta, porque mesmo os rios principais não tèm sido adequadamente amostrados e há muitos afluentes importantes que nunca foram trabalhados. Certos cursos dágua da Bacia Amazônica, com características peculiares (natureza química da água, por exemplo) apresentam, muitas vezes, espécies endêmicas. Em igarapés não muito grandes, razoavelmente amostrados, foram encontradas de 50 a 10 espécies de peixes, quantidade muito superior à encontrada em riachos de tamanho comparável na América do Norte. Muitas dessas espécies, originárias de riachos bem coletados na América do Sul, são endêmicas ou pelo menos ainda desconhecidas em outras regiōes.

Nos riachos localizados em regiões elevadas ao longo dos Andes, no escudo das Guianas, em bacias isoladas tais como os rios costeiros do leste do Brasil, e algumas bacias hidrográficas maiores, como por exemplo a do rio São Francisco no Brasil e a do lago de Maracaibo na Venezuela, parece existir um endemismo particularmente acentuado. $O$ lago Valencia, na Venezuela, também possuía um considerável grau de endemismo, mas, segundo Mago Leccia (in litt.), muitas das formas endêmicas são atualmente raras e podem mesmo ter desaparecido devido à introduçảo de um ciclídeo sul-americano do gênero Petenia. O mesmo fenômeno aconteceu no lago Titicaca, situado entre o Peru e a Bolívia, onde uma fauna endêmica de ciprinodontídeos do gênero Orestias tornou-se praticamente extinta devido à introdução da truta, originária da América do Norte e Europa. Estes fatos reforçam a necessidade de se coletar e estudar os peixes de áreas onde provavelmente existe endemismo, pois, se a fauna destas áreas não for descrita, um volume muito grande de informaçôes sobre a zoogeografia dos peixes de água doce da América do Sul poderá se perder. O endemismo e zoogeografia dos peixes de água doce sul-americanos são ainda pouco entendidos devido à insuficiência de coletas e ao parco conhecimento de suas relações filogenéticas.

Como na América do Norte, alguns peixes de água doce da América do Sul, especialmente as espécies de grande porte, têm distribuição geográfica ampla, exibindo pequena variaçáo de uma localidade para outra. Outros, especialmente os grupos de peixes pequenos, são representados por inúmeras espécies, como por exemplo os caracídeos dos gêneros Astyanax, Hyphessobrycon, Hemigrammus, Characidium e afins, ou siluriformes dos gêneros Loricaria e Corydoras. É entre estes e outros gêneros, que apresentam uma elevada taxa de especiação, que se espera encontrar muitos peixes desconhecidos devido ao alto grau de endemismo geográfico. Coleções adequadas de pequenos peixes muitas vezes proporcionam um aumento drástico do número de espécies conhecidas. No gênero Corydoras, pertencente ao grupo dos siluriformes, por exémplo, o número de espécies nominais atingiu mais que o dobro nos últimos 25 anos, indo de 50 a bem mais que 100 e isto principalmente graças a coletas exaustivas em certas áreas da América do Sul, como por exemplo o Suriname (veja Nijssen, 1967).

De um modo geral, as técnicas de amostragem na América do Sul têm sido limitadas. Técnicas de coleta aperfeiçoadas podem aumentar significativamente o número de espécies conhecidas. Apenas recentemente foi descoberta, com o uso de redes de malhas muito pequenas, toda uma fauna de caracídeos, constituída de espécies diminutas relacionadas ao gênero Characidium. No passado, estes peixes quase sempre escapavam através das malhas de redes inadequadas. Os aparelhos que emitem choques elétricos são especialmente eficientes para a coleta de espécies que vivem na lama ou areia do fundo, mas têm sido raramente utilizados na América do Sul. Muitos ambientes especiais têm sido negligenciados ou, no máximo trabalhados apenas 
esporadicamente. É o que acontece, por exempio, com uma série de corredeiras situadas acima de Manaus, no rio Negro, que contêm alguns siluriformes endêmicos que vivem na areia ou no fundo, coletados em 1925. Estas corredeiras foram exploradas apenas uma vez, embora uma coleta casual pequena tenha sido realizada posteriormente. Dois exemplares, aparentados aos bagres, coletados naquelas corredeiras, foram depois descobertos no sopé dos Andes, na Colômbia (Myers \& Weitzman, 1966) . Como não tem sido realizadas coletas nos ambientes em que estes peixes vivem, tanto no restante da Bacia Amazônica como na Bacia do Orinoco, não é possível afirmar se os exemplares coletados se restringem apenas às áreas onde foram encontrados, ou ocorrem em maior número em outras localidades. Tudo indica que a raridade seja mais decorrente da falta de coletas. Outro tipo de ambiente quase totalmente inexplorado é o das águas profundas do próprio rio Amazonas; há indícios de que esta zona abriga uma fauna de bagres hoje quase totalmente desconhecida (veja Böhlke, 1976). Exemplos dessas lacunas no levantamento da fauna são numerosos, mas os citados acima são suficientes para dimensionar o problema.

Tudo isto indica que não existe uma maneira razoável de estimar o número de espécies desconhecidas de peixes de água doce sulamericanos, mas uma coisa é absolutamente certa: o número deve ser muito mais elevado do que aquele existente nos Estados Unidos e Canadá; pode atingir até 30 ou $40 \%$, se considerarmos apenas as espécies de pequeno porte conhecidas. Uma estimativa das espécies maiores desconhecidas na América do Sul revelaria, provavelmente, percentagens bem maiores.

$\mathrm{O}$ segundo problema, relativo à qualidade das descrições dos peixes de água doce sulamericanos, é mais fácil de ser avaliado. Infelizmente, muitas das espécies que constituem esta fauna precisam ser redescritas de acordo com os padrões atuais, de tal forma que a identificação por meio dessas descrições possam tornar-se uma realidade prática. Além disso, os prổblemas de nomenclatura e validade de nomes científicos, tanto dos peixes pequenos como dos grandes, são numerosos $\mathrm{e}$ de difícil solução. Não existem biólogos sistematas bem treinados em número suficiente para preparar monografias, chaves ou manuais regionais, mesmo dos peixes utilizados em alimentação ou dos peixes comerciais grandes, que poderiam ser utilizados por pescadores, biologistas de pesca e técnicos ou autoridades governamentais interessadas na regulamentação da pesca. O exemplo citado anteriormente, relativo às dificuldades de identificação das espécies exploradas comercialmente e que aparecem no mercado de Manaus, é suficiente para ilustrar o problema.

Com uma fauna de peixes tão pouco conhecida, é difícil estudar adequadamente a ecologia ou a biologia da pesca de qualquer região, especialmente nos casos, aliás freqüentes, em que 25 a $50 \%$ das espécies de uma dada região não podem ser identificadas com certeza, mesmo quando, em casos excepcionais, quase toda a literatura sobre peixes de água doce da América do Sul está à disposição do investigador. Esta literatura raramente é encontrada em sua totalidade em instituições norte-americanas ou européias e na América do Sul poucas instituições possuem uma modesta representação.

\section{RELAÇõES FILOGENÉTICAS}

Bons estudos de relações filogenéticas de um grupo qualquer dependem da existência de levantamentos relativamente completos e também do conhecimento da morfologia e de outros aspectos das espécies que o compõem. Os caracteres usados em tais estudos devem ser avaliados quanto ao conteúdo de informação filogenética que contêm antes de serem utilizados para testar hipóteses filogenéticas. As hipóteses sobre relações filogenéticas dos "taxa" existentes em um grupo qualquer terão uma curta sobrevivência se uma grande percentagem da fauna considerada for desconhecida e novos "taxa" estiverem sendo continuamente descobertos e descritos. Trabalhos recentes (Weitzmann \& Fink, no prelo) demonstram que "taxa" recém-descritos fornecem evidências que muitas vezes proporcionam a rejeição de hipóteses filogenéticas antigas e mesmo a substituição de outras ainda recentes. 
O conhecimento das relaçỏes filogenéticas e da zoogeografia ou dos padrões de distribuição atuais dos peixes de água doce da América do Sul podem ser considerados, sem nenhum exagero, como ainda em sua infância. Para a maior parte dos grupos não existem hipóteses filogenéticas que podem ser consideradas acertaveis; o cunhecimento limitado que possuímos destes peixes é estritamente tipológico. Em outras palavras, certos peixes são reunidos em grupos porque possuem certos caracteres em comum, mas o valor da informação filogenética expressa por esses caracteres nunca foi testado. Na verdade, as evidências existentes sugerem que muitos dos caracteres usados atualmente para definir e relacionar gêneros e espécies, em muitos grupos de peixes de água doce sul-americanos, não contêm informaçāo filogenética útil; desta forma, tais caracteres têm sido mal interpretados e incorretamente usados nos estudos de filogenia. Vários autores, como por exemplo Eigenmann (1917) e Gregory \& Conrad (1938), discutiram alguns aspectos da filogenia dos Characoidei, mas, do ponto de vista crítico, suas idéias deixam muito a desejar, tanto em relação ao método científico, quanto ao modo de avaliação da informaçăo filogenética dos caracteres. Muitos autores não tiveram a grande e longa familiarização com os Characoidei experimentada por Eigenmann. Faltou-lhes o conhecimento intuitivo que levou Eigenmann (1917) pelo menos a entender que muitos dos gêneros que ele e seus colaboradores tinham considerado como bons indicadores de relaçōes filogenéticas, na verdade não poderiam ser considerados como tal. A maior parte dos trabalhos sobre filogenia, subsequente ao esforço desenvolvido por Eigenmann, baseou-se nas hipóteses filogenéticas preliminares deste autor e não contêm uma avaliação crítica e rigorosa da homologia dos caracteres utilizados e das hipóteses filogenéticas consideradas (Weitzman \& Fink, no prelo, tecem mais considerações sobre o assunto). Em resumo, um estudo adequado da filogenia dos peixes de água doce da América do Sul está apenas começando e sem ele não pode haver estudos razoăveis sobre a zoogeografia desses peixes. Outros aspectos, tais como ecologia e fisiologia de peixes, podem evoluir sem conhecimen. to filogenético, mas perdem muito de seu valor sem a contribuição unificadora da filogenia e da zoogeografia.

A possibilidade de estudar todos os aspectos gerais da biologia dos peixes de agua doce sul-americanos é limitada pela inventariação incompleta das espécies presentes e pelo escasso conhecimento da filogenia dos já conhecidos.

CONHECIMENTO DOS PEIXES DE ÁGUA DOCE SUL-AMERICANOS POR REGIÕES FAUNÍSTICAS

Para efeito de discussão, a fauna de peixes sul-americana pode ser artificialmente dividida em várias regiōes, mas deve ficar claro que o conhecimento de uma região depende e está relacionado ao conhecimento das regiōes adjacentes. Algumas destas regiōes têm sido melhor estudadas que outras, enquanto que algumas apresentam problemas peculiares $\mathrm{e}$ necessitam uma atenção imediata.

A fauna de peixes da Patagônia, que se estende do rio Negro na Argentina para o sul, difere consideravelmente da fauna das outras regiões ao norte e contém um número de espécies relativamente baixo. Eigenmann (1909) estudou esta fauna e algumas de suas relações zoogeográficas. Seu trabalho, juntamente com o de Ringuelet et al. (1967), contribuiu decisivamente para torná-la melhor conhecida do que a maior parte das demais faunas de peixes existentes na América do Sul. Apesar disto, ainda resta muito a fazer naquela área, pois tudo o que se conhece até agora daquela região, pode talvez ser comparado ao que foi feito na América do Norte em 1900 e, como um todo, a fauna patagônica não foi objeto de nenhum estudo zoogeográfico recente.

A fauna de peixes dos altiplanos andinos, confinada em sua maior parte a riachos torrenciais e poucos lagos de grandes dimensões, com algumas exceçőes importantes, parece ter derivado de gêneros com ancestrais nas partes baixas a leste. Esta fauna não é bem conhecida e é aparentemente pequena. Com exceção do estudo de Böhlke (1958:9-12) sobre Bryconamericus peruanus, praticamente nada se conhece sobre a distribuição de peixes através da Cordilheira Andina. A distribuição dos peixes encontrados nas elevações me- 
nores existentes ao norte, na Venezuela e Colômbia, é entretanto melhor conhecida. Estudos cuidadosos sobre endemismo, por um lado, e dispersão por meio da captura de afluente, de outro, nunca foram realizados em quaisquer das áreas montanhosas da América do Sul.

A fauna de peixes das planícies a oeste dos Andes pode ser subdividida em três áreas distintas. A que se situa ao sul de Santiago, Chile, é pequena e talvez possa ser relacionada à fauna patagônica citada anteriormente, embora sua distribuição através dos Andes não seja bem estudada. Entre Santiago e Lima (Peru) os riachos que correm a oeste dos Andes são pequenos e periódicos e não possuem uma verdadeira fauna de peixes de água doce. Entre Lima e a parte norte do Equador, os riachos que correm em direção oeste são pequenos, contêm uma fauna de peixes distinta, mas muito limitada em número de espécies. As espécies, nesta área, embora relacionadas às do leste dos Andes, são isoladas e revelam um elevado grau de endemismo. Foram discutidas por Eigenmann (1921), mas ainda são pouco conhecidas. As únicas drenagens verdadeiramente grandes a oeste dos Andes encontramse na Colômbia. Os peixes do rio Magdalena foram intensamente estudados por Steindachner $(1879,1880)$ e por Eigenmann (1920a, b, c e 1922). Esses peixes mostram uma grande afinidade com aqueles das planícies a leste, na Venezuela, mas esta fauna venezuelana, de modo geral, não é bem conhecida.

Tendo trabalhado na bacia de Maracaibo, parte ocidental da Venezuela, Schultz (1949) calculou que, naquela época, apenas cerca da metade da fauna de peixes tinha sido coletada; pouco se fez posteriormente nesta área. A fauna até agora descrita indica que as espécies da parte baixa de Maracaibo são semelhantes, e em alguns casos idênticas, às da bacia do Magdalena, enquanto que os peixes dos cursos superiores são, em linhas gerais, tanto semeIhantes aos da bacia do Orinoco como aos do Magdalena.

Alguns trabalhos pequenos têm sido publicados, descrevendo principalmente novos gêneros e espécies das partes central, leste e sul da Venezuela, mas pouco se conhece atualmente sobre os aspectos gerais da ictiologia desta região, que tem sido pouco explo- rada (veja Mago Leccia, 1970). Embora existam algumas coleções importantes da região na Universidade Central de Venezuela, Caracas, elas foram pouco estudadas. Não existe um trabalho faunístico de revisão abrangendo a área total e os relatos limitados que existem cobrem apenas alguns dos menores afluentes do rio Orinoco.

A fauna ictiológica da Guiana central foi bem revista, em 1912, ao nível de prospecção inicial, por Eigenmann; parte do Rupununi (especialmente a ecologia dos peixes) foi estudada por Rosemary Lowe-Mc Connell (1964). Tais estudos, entretanto, são zoogeograficamente limitados e nunca se tentou uma exploração total dos rios da Guiana. Os peixes do Suriname são parcialmente conhecidos graças aos antigos trabalhos de Bloch (1785-1795) e Bleeker (1864). Vários trabalhos, principalmente publicados por Boeseman (1968) em Leiden e por Nijssen (1967) em Amsterdã, representam contribuições para o conhecimento de fragmentos da fauna de peixes. Os dois últimos autores trabalharam com loricarídeos e calictídeos respectivamente. Esses autores e Hoedeman publicaram também descrições de alguns outros grupos de peixes de água doce do Suriname. Hoedeman (1959) fez uma revisão dos ciprinodontídeos desta área. A Guiana Francesa pode ser considerada a menos conhecida, embora Puyo (1949) tenha publicado um trabalho faunístico superficial dos peixes e Géry (1972b) tenha iniciado a descrição de alguns dos Characoidei.

Ao sul das áreas acima mencionadas, situa-se a enorme drenagem Amazônica. Muitas coletas têm sido feitas na parte inferior da $\mathrm{Ba}$ cia Amazônica, mas a área é tão grande que levantamentos relativamente completos só serão possíveis em um futuro distante. Uma grande parte do perímetro representado pelas terras altas da Bacia Amazônica tem sido pouco explorada, especialmente ao sul e ao norte da calha do rio. Com exceção dos siluriformes e ciclídeos, monografados por Alípio de Miranda Ribeiro (1911 e 1915, respectivamente), os peixes da região não são abrangidos em trabaIhos faunísticos gerais. O catálogo de peixes de água doce do Brasil, publicado por Fowler $(1948,1950,1951,1954)$, se usado com cautela, pode ser útil; freqüentemente inclui espé- 
cies extra-territoriais e contém numerosos erros. Os peixes da parte superior da Bacia Amazônica, a oeste, foram objeto de uma série de trabalhos, como por exemplo os de Cope $(1870,1872)$; os peixes da Amazônia peruana foram resumidamente tratados por Eigenmann \& Allen ( 1942). Infelizmente, ao relato de Eigenmann \& Allen, faltam descriçōes acuradas e o de Fowler (1945), que trata de toda a fauna de peixes de água doce do Peru, tem a mesma característica de seu trabalho sobre os peixes do Brasil, mencionado acima. Alguns dos afluentes amazônicos, tais como o rio Beni, foram relativamente bem coletados (Pearson, 1924J; muitos outros foram coletados em muito menor escala ou nem mesmo coletados. Böhlke (1958) e Géry (1972a) contribuiram para um melhor conhecimento dos Characoidei do Equador. Estes estudos incluem muitas espécies da drenagem amazônica no Equador.

Recentemente, graças aos esforços desenvolvidos pela Expedição Permanente da Amazônia (EPA), criada por iniciativa oficial com apoio financeiro da Fundação de Amparo à Pesquisa do Estado de São Paulo, organizada e dirigida por Paulo Emílio Vanzolini, coletas maciças têm sido feitas em quase toda a calha mestra do Amazonas brasileiro e alguns de seus principais afluentes. A EPA tem recebido colaboração de numerosas entidades brasileiras, principalmente do Conselho Nacional de Desenvolvimento Científico e Tecnológico e do Instituto Nacional de Pesquisas da Amazônia.

Como resultado das diversas expedições realizadas desde 1967 , foram coletadas cerca de 200.000 peixes, depositados no Museu de Zoologia da Universidade de Săo Paulo. Esta é a maior coleção de peixes da Amazônia brasileira existente no mundo e como tal representa um importante recurso para qualquer estudo faunístico. Embora boa parte do material coletado não tenha ainda sido estudada, vários trabalhos recentes sobre peixes amazônicos foram publicados em decorrência dos esforços desenvolvidos pela EPA (Böhlke \& Mc Cosker, 1975; Britski \& Garavello, 1978; Dawson, 1974; Menezes, 1974; Nijssen, 1971; Roberts, 1970, 1971, 1972; Weitzman, 1977, 1978; Weitzman \& Kanazawa, 1976, 1977, 1978).

As coleções da Expedição Catherwood ao Peru, existentes na Academy of Natural Scien- ces, Filadelfia, e ainda não estudadas, constituem também um recurso adicional para pesquisas futuras sobre peixes da Bacia Amazônica.

As regiōes montanhosas do leste do Brasil são drenadas por numerosos rios que desembocam no Oceano Atlântico e também por rios que correm em direção norte para o Amazonas e em direção sul para o rio Paraná. A maior destas drenagens é a do rio São Francisco, cuja fauna de peixes foi apenas parcialmente descrita por Steindachner, Haseman e Eigenmann em várias publicações pequenas. Os peixes dos rios menores do leste brasileiro têm recebido uma atenção maior ou menor; alguns rios dessa área são ainda praticamente ignorados. Como um todo, a área ainda não foi convenientemente explorada, mesmo nas cercanias de grandes centros urbanos como São Paulo e Rio de Janeiro.

Os peixes do sistema Paraná-Paraguai, apesar de constituírem uma fauna rica e numerosa, são relativamente pouco estudados. Até há bem pouco tempo existiam apenas pequenas coleçōes esparsas na Europa, América do Norte e América do Sul, que serviram de base a alguns trabalhos. Atualmente existem coleções do Baixo Paraná depositadas principalmente nos museus de La Plata e Buenos Aires, na Argentina, e uma grande coleção do Alto Paraná depositada no Museu de Zoologia da Universidade de São Paulo. Esta última resultou de um convênio entre o Museu de Zoologia da USP e as Centrais Elétricas de São Paulo, órgăo do Governo do Estado de São Paulo. Foram feitas diversas coletas no rio Paraná entre 1964 e 1972, durante a construção do complexo hidrelétrico de Urubupungá, que abrange as usinas de ilha Solteira e Jupiá. Graças ao apoio recebido do governo estadual na época, foram coletados cerca de 15.000 peixes, em grande parte identificados e incluidos nas coleções do Museu de Zoologia da USP. Os peixes do rio Paraguai são conhecidos através de publicações isoladas de diversos autores, principalmente Eigenmann \& Kennedy (1903), Eigenmann \& Ogle (1907) e Eigenmann, McAtee \& Ward (1907), baseadas em coleçōes que representam apenas uma pequena parte da enorme fauna do sistema hidrográfico do rio Paraguai. Pode-se concluir, portanto, que o 
conhecimento dos peixes do grande sistema Paraná-Paraguai é ainda muito limitado em relação ao tamanho e à complexidade de sua fauna. O rio Uruguai, que também faz parte do sistema Paraná-Paraguai e encontra este último na região do Prata, é ainda menos coletado e tudo o que se conhece resulta praticamente dos trabalhos de Devincenzi (1924) e Devincenzi \& Teague (1942).

Há, talvez, duas áreas da América do Sul que, com relação ao conhecimento da fauna de peixes de água doce, podem ser comparadas a outras áreas do mundo: Guiana e Bacia do Magdalena. Mesmo nestas, em termos de coletas e estudos, o que se conhece pode ser comparado ao que foi feito nos rios do Canadá e Estados Unidos por volta de 1900. Em uma comparação análoga, Myers (1975) afirmou:

In truth, freshwater taxonomic ichthyology in a large part of Brazil, Uruguay, Paraguay, Bolivia, northern Argentina and the Oriente of Peru, Ecuador, and Colombia is at present in approximately the same state that the ornithology of these same areas was in 1830 or 1840 .

Acreditamos que não haja nenhum exagero nesta afirmação.

Não houve ainda uma tentativa séria de estudo em grande escala dos peixes de água doce da América do Sul, levando em consideração as comunidades bióticas às quais eles pertencem ou de se averiguar em detalhe as implicações zoogeográficas de suas distribuições. A enorme falta de conhecimento ainda existente sobre a distribuição geográfica e os ambientes ecológicos desses peixes, constitui um sério obstáculo ao sucesso de tais estudos.

A discussão acima dá uma idéia resumida do conhecimento atual dos peixes sul-americanos a partir de regiões geográficas, definidas apenas com base em aspectos do relevo e bacias hidrográficas. No futuro, entretanto, uma atenção muito grande deve ser dedicada a estudos comparativos de distribuição, levando-se em consideração o interrelacionamento geográfico de faunas e floras e a história geológica dos sistemas fluviais.
Problemas INERENTES AO ESTUDO DA SISTEMÁTICA DOS PEIXES DE ÁGUA DOCE DA AMÉRICA DO SUL

O estudo dos peixes de água doce da América do Sul apresenta problemas comuns ao estudo de faunas de peixes em muitas outras partes do mundo: bibliografia obtida com dificuldade, ou pelo menos muito dispendiosa de ser adquirida; os exemplares para comparação, necessários para estudos adequados, encontram-se espalhados por diversos museus do mundo; coleções de áreas geográficas importantes não existem ou, quando existem, não são representativas; e exemplares importantes (tipos e outros), em alguns casos foram destruídos, perdidos ou estragaram-se com o tempo, muitas vezes devido à falta de cuidado. Estas dificuldades, sérias para o ictiólogo norte-americano e europeu, são muitas vezes danosas e desestimulantes para o ictiólogo sulamericano que estuda sua própria fauna. Infelizmente, os ictiólogos sul-americanos são muitas vezes mal compreendidos por seus colegas de outras áreas da ciência não familiarizados com estudos de sistemática. A impossibilidade de identificar exemplares que chegam às mãos do ictiólogo ou do biólogo da pesca é muitas vezes interpretada como incompetência, quando, de fato, não é isto que ocorre. A falta de bibliografia e de coleções para ccmparações constituem os problemas mais agudos que o ictiólogo tem que enfrentar. Muito da bibliografia sobre ictiologia da América do Sul foi publicado em periódicos de difícil obtenção e os trabalhos faunísticos clássicos deixaram de ser impressos há muito tempo. Muitos fazem parte do rol de livros raros e são extremamente caros. Apenas uns poucos foram reimpressos e mesmo estas reimpressões são caras. Parte do que está sendo publicado atualmente não chega a bibliotecas e instituições importantes da América do Sul. Em tais circunstâncias, não apenas o trabalho científico é prejudicado, mas mesmo uma simples identificação torna-se às vezes impossível.

Coleções realmente adequadas para o estudo da sistemática de peixes na América do Sul, comparáveis às que existem na América do Norte para estudos de peixes norte-ameri- 
canos, forçosamente teriam que englobar um número muito maior de exemplares e seriam muitas vezes maiores que as coleções de peixes de água doce norte-americanos atualmente existentes nos Estados Unidos e Canadá. De acordo com Lachner et al. (1976), as coleçóes do Canadá e Estados Unidos contêm aproximadamente 36 milhões de exemplares e incluem representantes de praticamente todo o mundo, a proporção de peixes norte-americanos (não especificados) sendo relativamente modesta. As dificuldades de obtenção e manutenção de grandes coleções de peixes de água doce sul-americanos são imensas, principalmente devido à não existência de pessoal bem treinado e qualificado em número suficiente. Um programa cooperativo envolvendo ictiólogos sul-americanos, norte-americanos e europeus, possivelmente constituiria a condição ideal para resolver grande parte do problema.

\section{RECOMENDAÇÕES}

Com base na discussão feita, é evidente que ainda falta muito para que se tenha um conhecimento adequado dos peixes de água doce da América do Sul. Em nosso entender as tentativas para corrigir esta situação devem se fundamentar nos seguintes objetivos: (1) organizar e aumentar o conhecimento dos peixes de água doce sul-americanos, de tal forma que sua importância como fonte de alimento possa ser melhor avaliada por meio de um estudo harmônico de sua taxonomia, filogenia, zoogeografia e ecologia; (2) utilizar a informação assim obtida para tentar preservar do melhor modo possivel e de acordo com as atividades e necessidades humanas, o valor científico e estético desta fauna complexa. Tendo em vista as mudanças inevitáveis da paisagem, que fatalmente ocorrerão com a ocupação humana, dever-se-ia tentar elaborar um trabalho onde ficassem registradas as informações sobre a fauna natural de peixes, para que no futuro se tenha uma idéia de sua importância, antes do "habitat" ser alterado pelo homem. Tal documento não teria apenas uma importância histórica, mas serviria de base para medidas de conservação. As coleções de museu são de importância primordial para que se tenha tal tipo de registro, e no caso de alteração do ambiente, elas constituem a única fonte para reconstrução histórica da fauna.

A medida mais importante, em qualquer tentativa conjugada para estudar a fauna de peixes da América do Sul, deveria ser a de inventariar as áreas que estão em perigo imediato de alteração de ambiente, as áreas onde a construção de grandes barragens está projetada ou iniciada, as áreas onde estão previstas alterações devidas a projetos de agricultura e industriais e as áreas onde está prevista a introdução de espécies exóticas em conexão com projetos de piscicultura. Além desta programação de emergência, deveria haver um esforço conjunto, planejado por parte das autoridades envolvidas em futuros programas de coletas, no sentido de proporcionar condições para a formação e, assim, aumentar o número de técnicos e profissionais qualificados nas respectivas áreas de interesse, para coleta, pesquisa e manutenção de coleções.

Uma medida preliminar importante que deveria constar de qualquer programação futura relativa ao esforço conjunto de coletas, é a tentativa de levantamento das atuais coleções de peixes sul-americanos existentes no mundo. Tal levantamento deveria ser feito com o propósito de estabelecer-se onde são mantidas coleções importantes, suas condições, tamanho e o que elas contêm. O levantamento deveria incluir informaçōes sobre exemplarestipo e áreas geográficas representadas. Coleções importantes, moderadas a grandes, existem nas seguintes cidades: Paris, Londres, Viena, São Francisco (Califórnia), Chicago, Cambridge (Massachusetts), Washington, D. C. , Filadélfia, São Paulo, Caracas, Amsterdã, Leiden e Rio de Janeiro. Há várias outras coleções de peixes que contêm menores quantidades de peixes de água doce da América do Sul. Algumas destas coleções são importantes em virtude do número de tipos que contêm (por exemplo, Ann Arbor e Nova lorque) Existe uma importante coleção particular na França, mas coleções particulares deveriam ser desencorajadas por causa da grande probabilidade de perda. As informações obtidas com este levantamento permitiriam uma série de recomendações para o estabelecimento e manutenção de futuras coleções. 
Uma programação a longo prazo, com o objetivo de desenvolver o estudo dos peixes de água doce da América do Sul, exigiria talvez um estorço conjunto de âmbito internacional. Dever-se-ia recomendar o estabelecimento de coleçöes permanentes em paises sulamericanos e uma ênfase especial deveria ser dada à necessidade de um programa constante de intercâmbio. Sem este esforço conjunto, o conhecimento dos peixes de água doce sulamericanos possivelmente evoluirá lentamente, de uma forma bem aquém da que seria desejável para se ter uma idéia razoável de como é ou era esta fauna. Do mesmo modo, informaçoes importantes e úteis, relativas à melhor utilização dos peixes de água doce em benefício do homem, serão postergadas por iongo tempo.

\section{APENDICE}

As considerações abaixo são feitas com o intuito de chamar a atenção para alguns dos problemas relacionados à coleta de peixes de água doce da América do Sul.

Qualquer programa de inventariação de fauna deveria levar em consideração a possibilidade de coletas em todas as épocas do ano. As amostragens são mais fáceis na estação seca, mas deveriam ser feitas durante todo o ano para que fatores como crescimento, desova e migração pudessem ser analisados. As coletas de peixes de água doce nos trópicos têm se restringido à época seca, quando os peixes podem estar concentrados em áreas lagunares. Aí podem ser capturados mais facilmente do que durante a época de cheia. Tais coletas são importantes para o conhecimento de espécies pequenas e de tamanho médio e devem ser feitas em larga escala. Entretanto, dever-se-ia também lembrar que as espécies maiores, adultas, muitas vezes estão confinadas às partes mais fundas dos rios e, neste caso, as coletas nas regiões lagunares rasas não refletiriam a composição da fauna de espécies fluviais Experiências prévias revelaram que coletas feitas sempre na mesma época do ano produzem apenas exemplares de um determinado tamanho, frequentemente imaturos. Muitas coleções consistem de centenas de exemplares jovens e nenhum adulto, enquanto que outras contêm poucos adultos. Em muitos casos, adultos e jovens pertencentes a classes de idade diferentes, näo podem ser adequadamente comparados e o pesquisador é incapaz de determinar se está diante de uma ou mais espécies.

Todos os principais lagos e rios da América do Sul deveriam ser amostrados, mas algum critério prévio deveria ser adotado para que se tenha uma representação razoável dos diversos sítios de coleta. A área a ser coletada é muito grande para ser totalmente amostrada a curto ou médio prazo. A fauna dos cursos inferiores de qualquer sistema hidrográfico aparentemente não varia muito $\mathrm{e}$, neste caso, coletas intensivas em pontos estratégicos seriam suficientes em muitos casos, mas, como foi dito, amostragens durante $o$ ano todo nesses ambientes são essenciais. Áreas onde parece ocorrer endemismo, tais como cabeceiras de afluentes de grandes rios com cursos independentes que desembocam diretamente no mar, etc., deveriam ser intensamente exploradas e coletadas.

A determinação das épocas e rotas de migração e a descoberta de áreas de desova e criação são muito importantes para a proteção das espécies, devido à possibilidade de construção de barragens e possivel destruição de ambientes naturais. A seguinte afirmação é oportuna, especialmente porque fol escrita há mais de 25 anos.

In all of South America, the migration path of not a single migratory fluviatile food fish has ever been worked out. These studies cannot be completed quickly. They require several years. Dams for power and irrigation are already planned for several large South American rivers. The fishery resources of these rivers are comparatively much more important to the indigenous populations than are those of North American rivers. The need for fish study is great and the time is very short. (Myers, 1959).

Até certo ponto, esta afirmação poderia ser feita hoje.

Todas as técnicas de coleta deveriam ser tentadas e todos os tipos de aparelhos empregados. Deveriam ser incluídos diversos tipos de redes (cerco, picaré, etc.), puçás, armad:lhas, anzóis e linhas, timbó ou equivalente, equpiamentos de pesca elétrica e arrastões de 
fundo. Embora a utilização de arrastões de fundo possa vir a ser problemática, deveria ser tentada, pois poderá produzir resultados compensadores, como se pode depreender do seguinte exemplo:

The... specimens... taken with an otter trawl from the Amazonas... Only one downstream haul was made, because of the swiftness of the current and the many snags in the bottom, but this caught a fascinating group of mostly new and rare catfishes... This suggests that more bottom sampling should be attempted in large South American rivers. (Böhlke, 1970).

Amostragens da fauna que habita as águas fundas dos rios da Amazônia e Orinoco nunca foram feitas.

Ênfase especial deveria ser dada às coletas noturnas, que muitas vezes revelam espécies diferentes das que são coletadas durante o dia.

\section{SUMMARY}

The fish fauna of the fresh waters of South America is relatively poorly known compared with those of the remainder of the world.

Current progress in the economic growth of many areas of South America, forcing alteration of the habitat by deforestation, agriculture, and industrialization, makes it imperative that in many areas the fishes be sampled soon, before they are lost.

The descriptive phase of the study of the freshwater fish fauna in South America has proceeded in three historical periods. The first period occurred from 1750 to about 1866 during which a moderate share of the larger market fishes were described by European zoologists. The second period took place from 1866 to about 1930 and was a period of rapid description of small and large species by ichthyologists both in Europe and North America. The third period, from 1930 to the present, has been in part a period of further description in North America, Europe and South America. It has also been a period in which the complexity of the problems facing systematic ichthyology in South America have been more fully understood.

Aithough no real estimate can be made, perhaps as much as 30 to $40 \%$ of the freshwater fish fauna of South America remains to be described and our current descriptive or inventory knowledge of this fauna is similar to our knowledge of the freshwater fish fauna of the United States and Canada about 100 years ago. There are currently 2,500 to 3,000 known species in South America and the ultimate figure could rise to 5,000 species.
Study of the phylogenetic relationships and zoogeography of South American freshwater fishes is in its infancy.

The unavailability of old ichthyological literature, comparative museum specimens, and the lack of faunal reports for most areas are all factors making it difficult and often impossible for ichthyologists and fisheries biologists to effectively pursue their professions in South America. These same factors inhibit studies of South American fishes in countries outside South America.

Many species of fishes, especially those larger food fishes described before 1870, need study and Iedescription so that literature suitable for simple identification may be provided to the fisheries biologist and others concerned with economically important fishes. However, in addition to this, most groups of South American freshwater fishes are in need of modern taxonomic revision before successful research on these fishes can be performed in other disciplines

\section{BIBLIOGRAFIA CITADA}

ANÔNIMO

1970 - Annotated chronological bibliography of the publications of George Sprague Myers (to the end of 1969). Proc. California Acad. Sci., (4)38(2) : 19-52.

Agassiz, L. \& Agassiz, E.C.

1868 - A journey in Brazil. Ticknor and Fields, Boston: $x i x+540 \mathrm{pp}$.

BLEEKER, $\mathbf{P}$.

1864 - Description des espèces de silures de Suriname conservées aux Musées de Leide et d'Amsterdam. Erven Loosjes, Haarlem : 104 pp., 16 pls.

BLOCH, M.E.

1785-1795 - Naturgeschichte der ausländischen Fische. Berlin, 9 vols., texto +324 pls.

BOESEMAN, M.

1968 - The genus Hypostomus Lacépède, 1803, and its Surinam representatives (Siluriformes, Loricariidae). Zool. Verhand. Leiden, (99) : 89 pp., 18 pls.

BÖHLKE, J.E.

1958 - Studies on fishes of the family Characidae. N. 14 . A report on several extensive recent collections from Ecuador. Proc. Acad. Nat. Sci. Philadelphia, $110: 1-121$.

1970 - A new species of the doradid catfish genus Leptodoras, with comments on related forms. Proc. California Acad. Sci., (4)38(3) : 53-62. 
BÖHLKE, J.E. \& MC COSKER, J.E.

1975 - The status of the ophichthid eel genera Caecula Vahl and Sphagebranchus Bloch and the description of a new species from fresh waters in Brazil. Proc. Acad. Nat. Sci. Philadelphia, 127(1) : 1-11.

Britski, H.A. \& Garavello, J.C.

1978 - Sobre Leporinus octofasciatus Steindachner da Bacia do Paraná (Pisces, Anostomidae). Pap. Avul. Zool. S. Pau1o, 31(16) : 237-250.

Castelnau, F. de

1855 - Expédition dans les parties centrales de l'Amérique du Sud... pendant les années 1843 à 1847. 14 vols. in 13 ; part 7 , Zoologie. Animaux nouveau ou rares... de l'Amérique du Sud, 3 vols. Tome 2, Poissons: P. Bertrand, Paris: xii +112 pp., 50 pls.

COHEN, D.M.

1970 - How many recent fishes are there? Proc. California Acad. Sci., (4)38(17) : 341-346.

COPE, E.D.

1870 - Contribution to the icthyology of the Maranőn. Proc. Amer. Philos. Soc., 11 : 559-570.

1872 - On the fishes of the Ambyiacu River. Proc. Acad. Nat. Sci. Philadelphia, 23 : 250-294, pls. 3-17.

CUVIer, G. \& VAlenciennes, A.

1828-1849 - Histoire naturelle des poissons. F.G. Levrault, Paris. 22 vols. texto +4 vols. pls.

DAHL, G.

1971 - Los peces del norte de Colombia. Ministerio de Agricultura, Instituto de Desarollo de los Recursos Naturales Renovables, INDERENA. Bogotá: xvii +391 pp.

DAwson, C.E.

1974 - Pseudophalus brasiliensis (Pisces, Singnathidae), a new fresh water pipefish from Brazil. Proc. Biol. Soc. Washington, $87: 405-410$

DeVINCENZI, G.J.

1924 - Peces del Uruguay. Anal. Mus. Nac. Montevideo, 1(2):139-290, 13-14 pls.

Devincenzi, G.J. \& Teague, G.W.

1942 - Ictiofauna del rio Uruguay Medio. Ibidem, (2)5(4):1-104, pls. 1-6.

DUNCKER, G.

1914 - Generalindex zu Franz Steindachners ichthyologischen Mitteilungen, Notizen und Beiträgen. Mitteilungen aus dem Naturhischen Museum in Hamburg, 31: 287-352.
Eigenmann, C.H.

1909 - The fresh-water fishes of Patagonia and an examination of the ArchiplataArchelenis theory. Rep. Princeton Univ. Exped. Patagonia, 1896-1899 (Zool.), 3(1):225-374, pls. 30-37.

1910 - Catalogue of the fresh-water fishes of tropical and south temperate America. Rep. Princeton Univ. Exped. Patagonia, 1896-1899 (Zool.), 3(4):375-511.

1912 - The freshwater fishes of British Guiana, including a study of the ecological grouping of species, and the relation of the fauna of the plateau to that of the lowlands. Mem. Carnegie Mus., 5:xvii +578 pp., 103 pls.

1917-1929 - The American Characidae. Mem. Mus. Comp. Zool., Harvard College, 43(1-5); pt. 5 em coautoria com George S. Myers; veja citação completa em Eigenmann \& Allen, 1942.

$1920 \mathrm{a}$ - South America west of the Maracaibo, Orinoco, Amazon, and Titicaca basins, and the horizontal distribution of its fresh-water fishes. Indiana Univ. Studies, 7(45):1-24.

$1920 \mathrm{~b}$ - The fishes of the rivers draining the western slope of the Cordillera Occidental of Colombia, rios Atrato, San Juan, Dagua and Patia. Indiana Univ. Studies, 7(46):1-19.

$1920 \mathrm{c}$ - The Magdalena basin and the horizontal and vertical distribution of its fishes. Indiana Univ. Studies, $7(47 \mathrm{~b}): 21-34$.

1921 - The origin and distribution of the genera of the fishes of South America west of the Maracaibo, Orinoco, Amazon, and Titicaca basins. Proc. Amer. Philos. Soc., 60:1-6.

1922 - The fishes of Western South America, Part I. Mem. Carnegie Mus., 9(1):346 pp., 37 pls.

1927 - The fresh-water fishes of Chile. Mem. Nat. Acad. Sci., 22:63 pp., 16 pls.

Eigenmann, C.H. \& Allen, W.R.

1942 - Fishes of Western South America. University of Kentucky, Lexington: $\mathrm{xv}+494$ pp., mapa.

Eigenmann, C.H. \& Eigenmann, R.S.

1890 - A revision of the South American Nematognathi or cat-fishes. Occ. Pap. California Acad. Sci., (1):508 pp., mapa.

1891 - A catalogue of the fresh-water fishes of South America. Proc. U.S. Nat. Mus., 14(842):1-81.

Eigenmann, C.H. \& Kennedy, C.H.

1903 - On a collection of fishes from Paraguay, with a synopsis of the American genera of cichlids. Proc. Acad. Nat. Sci. Philadelphia, 55:497-537. 
Eigenmann, C.H.; Mcatee, W.L. \& Ward, D.P. 1907 - On further collections of fishes from Paraguay, Ann. Carnegie Mus., 4(2) : 109-157, pls. 31-35.

Etgenmann, C.H. \& Ogle, F.

1907 - An annotated list of characin fishes in the United States National Museum of Indiana University with description of new species. Proc. U.S. Nat. Mus., $33: 1-36,8$ figs.

FiLIS, M.M.

1913 - The gymnotid eels of tropical America. Mem. Carnegie Mus., 6(3):109-195, pls 15-23.

FERREIRA, A.R.

1971 - Viagem filosófica pelas capitanias do Grão Pará, Rio Negro, Mato Grosso e Cuiabá. Iconografia, II, Zoologia. Ed. Conselho Federal de Cultura, Rio de Janeiro: viii, 168 pls, vii.

1972 - Viagem filosófica pelas capitanias do Grão Pará, Rio Negro, Mato Grosso e Cuiabá. Memorias, Zoologia, Botânica. Ed. Conselho Federal de Cultura, Rio de Janeiro: 264 pp., 4 pls.

FOWLER, H.W.

1945 - Los peces del Peru. Catalogo sistematico de los peces que habitan en aguas peruanas, 298 pp., 92 figs. Mus. Hist. Nat. "Javier Prado", Univ. Mayor de San Marcos, Lima.

1948 - Os peixes de água doce do Brasil (1a entrega). Arq. Zool. São Paulo, 6:1-204.

1950 - Os peixes de água doce do Brasil (2a entrega). Arq. Zool. São Paulo, 6:205-404.

1951 - Os peixes de água doce do Brasil (3a. entrega). Arq. Zool. São Paulo, 6:405-628.

1954 - Os peixes de água doce do Brasil (4a. entrega). Arq. Zool. São Paulo, 9: i.j $+1-400$.

GÉRY, J.

1972a - Contribution à l'étude des poissons characoïdes de 1'Equateur. Acta Humboldtiana, Ser. Geol., Palaeont. et Biol., (2): $1-110,8 \mathrm{pls}$.

$1972 \mathrm{~b}$ - Poissons characoïdes des Guyanes. I. Généralités. II. Famille des Serrasalmidae. Zool, Verhand. Leiden: $250 \mathrm{pp}$., 16 pls.

GodoY, M.P. DE

1975 - Peixes do Brasil. Subordem Characoidei. Bacia do rio Mogi-Guaçu. Piracicaba, Ed. Franciscana, SP, 4 vols.

GREGORY, W.K. \& CONRAD, G.M.

1938 - The phylogeny of characin fishes. Zoologica, New York, 23(4):319-360.
GÜNTHER, A.

1859-1870 - Catalogue of the fishes of the British Museum (vários títulos individuais). London, vols. I-VIII

HeCKel, J.

1840 - Johann Natterer's neue Flussfische Brasilien's nach den Beobachtungen und Mitteilungen des Entdeckers beschrieben von Jacob Heckel. An. Wiener Mus. Naturgesch, 2:327-470.

HoEdeman, J.J.

1959 - Rivulid fishes of Suriname and other Guyanas, with a preliminary review of the genus Rivulus. Studies on the Fauna of Suriname and other Guyanas, 3(7): 44-98, 5 pls.

JENKINS, R.E.

1976 - A list of undescribed freshwater fish species of continental United States and Canada, with additions to the 1970 checklist. Copeia, 1976 (3):642-644.

JENYNS, L

1842 - The Zoology of the Voyage of the H.M.S. Beagle... Smith, Elder and Co., London, Part IV, Fish: xvi+172 pp., $29 \mathrm{pls}$.

KNER, $R$.

1853 - Die Panzerwelse des KK. Hof-naturalien-Cabinetse zu Wien. 1. Abtteilung. Loricsrinae, Denks, K. Akad. Wiss., Wien, $6: 65-98,8$ pls,

1854 - Die Hypostomiden. Zweite Hauptgruppe der Familie der Panzerfische. (Loricata vel Goniodontes), Denks, K. Akad. Wiss., Wien, $7: 251-286,5$ pls.

1855 - Ichthyologische Beiträge. I. Uber die Gattungen Aspredo und Chaca C.V. aus der Familie der Welse (Siluroidei), Sitz. K. Akad. Wiss., Wien, 17:92-162, 6 pls

1858 - Ichthyologische Beiträge. II. Abtheilung. Sitz. K. Akad. Wiss, Wien, 26:373-448, 9 pls.

1859 - Zur Familie der Characinen. III. Folge der Ichthyologischen Beiträge. Denks. K. Akad. Wiss,, Wien, 17:137-182, 9 pls. e idem, II. Abtheilung, 18:9-62, 8 pls.

LachNer, E.A.; ATz, J.W.; BArlow, G.W.; Collette, B.B.; LAVenberg, R.J.; Robins, C.R. \& Schultz, R.J.

1976 - A national plan for icthyology / a report to the American Society of Ichthyolo. gists and Herpetologists by the ASIH Advisory Committee: 90 pp. +7 appendices; processed report.

Linnaeus, C.

1758 - Systema Naturae... Editio decima, reformata. Holmiae, 1:239-338. 
LOWE (MC CONNELL), R.H.

1964 - The fishes of the Rupununi savanna district of British Guiana, South America. Part 1. Ecological groupings of fish species and effects of the seasonal cycle on the fish. Journ. Linn. Soc., London, (Zoology), 45(304):103-144.

1975 - Fish communities in tropical fresh waters. London and New York, Longman : $x v i i+337 \mathrm{pp}$.

Mago-Leccia, $\mathbf{F}$.

1970 - Lista de los peces de Venezuela, incluyendo un estudio preliminar sobre la ictiogeografia del país. Caracas, Ministerio de Agricultura y Cria : $283 \mathrm{pp}$.

MARCGRAVE, G.

1648 - Historiae rerum naturalium Brasiliae... ( 8 partes: $1-292$; parte 4 , peixes: 142-181) in Piso, G. \& Marcgrave, G., Historia naturalis Brasiliae, auspicio et beneficio illustris I. Mauritii Com. Nassau..., Lugdun. Batavorum apud Franciscum Hackium, et Amstelodami, apud Lud. Elzeverium.

MENEZES, N.A.

1974 - On the Cynopotaminae, a new subfamily of Characidae (Osteichthyes, Ostariophysi, Characoidei). Arq. Zool. S. Pau16, 28(2) : 1-91.

MÜLleR, J. \& TROSCHEL, F.H.

1845-1849 - Horae Ichthyologicae. Beschreibung und Abbildung neuer Fische. Berlin. Partes 1-2, 1845: 40 pp., 11 pls.; parte 3 , 1849: 28 pp., 5 pls.

MYERS, G.S.

1927 - Descriptions of new South American fresh-water fishes collected by Dr. Carl Ternetz. Bull. Mus. Comp. Zool., Harvard College, 68(3):107-135.

1943 - Amoenitates Biologicae. The influence of Louis Agassiz on the ichthyology of Brazil. Rev. Bras. Biol., 3(1):127-133.

1949 - Initial steps in the conservation of fresh-water fisheries in tropical South America with remarks on fishery resources in general. Proc. Inter-American Conf. Cons. Ren. Nat. Res., Denver, Colorado, 1948 : 501-506.

1975 - A note on the genus Otothyris Myers (Pisces; Loricariidae). Santa Cruz Nat., $1: 8$.

MYers, G.S. \& WeITZMAN, S.H.

1966 - Two remarkable new trichomycterid catfishes from the Amazon basin in Brazil and Colombia. Journ. Zool. London, 149 : 277-287.
NIJSSEN, $\mathrm{H}$.

1970 - Revision of the Surinam catfishes of the genus Corydoras Lacépède, 1803 (Pisces, Siluriformes, Callichthyidae). Beaufortia, 18(230) : 1-75.

1971 - Two new species and one new subspecies of the South American genus Corydoras (Pisces, Siluriformes, Callichthyidae). Beaufortia, 19(250): 89-98.

PAYNE, F.

1928 - Carl H. Eigenmann. Proc. Indiana Acad. Sci., 37 (for 1927) : 35-46.

PeARson, N.E.

1924 - The fishes of the eastern slope of the Andes. I. The fishes of the rio Beni basin, Bolivia, collected by the Mulford Expedition. Indiana Univ. Stud., 11(64): 1-83.

PUYo, J.

1949 - Poissons de la Guyane Français. Fauna de l'Empire Français, XII. Librairie La Rose, Paris: $280 \mathrm{pp}$.

RIBeIro, A. DE M.

1911 - Fauna Brasiliense. Peixes. IV (A) Eleuterobranchios Aspirophoros. Archos. Mus. nac., Rio de Janeiro, 16:1-504, pls. 22-54.

1915 - Fauna Brasiliense. Peixes. V. (Eleuterobranchios Aspirophoros). Physoclisti. Archos. Mus, nac., Rio de Janeiro, $17: 679 \mathrm{pp}$.

RINGUElet, R.A.; ARAMBURU, R.H. \& ARAMBURU, A. A: DH

1967 - Los peces Argentinos de agua dulce. Provincia de Buenos Aires. Comisión de Investigacion Cientifica, La Plata: 602 pp.

ROBERTS, T.R.

1970 - Description, osteology and relationship of the Amazonian cyprinodont fish Fluviphylax pygmaeus (Myers \& CarvaIho). Breviora, (370) : 1-28.

1971 - Micromischodus sugillatus, a new Hemiodontid Characin fish from Brazil, and its relationship to the Chilodontidae. Breviora, (367) : 1-25.

1972 - Ecology of fishes in the Amazon and Congo basins. Bull. Mus. Comp. Zool., $143(2): 117-147$.

SCHOMBURGK, $\mathbf{R}$.

1848 - Reisen in Britisch-Guiana in den Jahren 1840-1844. Im Auftrag Sr. Majestät des Königs von Preussen ausgeführt von Richard Schomburgk. Nebst einer Fauna und Flora Guiana's nach Vorlagen von Joahannes Müller, Ehrenberg, Erichson, Klotzsch, Troschel, Cabinis und andern. J.J. Weber, Leipzig, 3:618-644. 
SCHOMBURGK, R.H.

1841a - R.H. Schomburgk's Reisen in Guiana und am Orinoco während der Jahren 1835-9. 2 vols. Leipzig.

$1841 \mathrm{~b}$ - The natural history of the fishes of Guiana, part I. W. Jardine's Naturalist's Library, Ichthyology, 3:263 pp., 34 pls.

1843 - The natural history of the fishes of Guiana, part II. W. Jardine's Naturalist's Likrary, Ichthyology, 5:214 pp., 32 pls.

SCHULTZ, L.P.

$1944 \mathrm{a}$ - The catfishes of Venezuela, with descriptions of thirtyeight new forms. Proc. U.S. Natl. Mus., 94(3172):173-338, 14 pls.

$1944 \mathrm{~b}$ - The fishes of the family Characinidae from Venezuela, with descriptions of seventeen new forms. Proc. U.S. Natl. Mus,, 95(3181) : 235-367.

1949 - A further contribution to the ichthyology of Venezuela. Proc. U.S. Nati. Mus., $99(3235): 1-211,3$ pls.

SpIx, J.B. \& Agassiz, L.

1829-1831 - Selecta genera et species piscium quos in itinere per Brasiliam... C. Wolf, Monachii: i-xvi, i-ii, 1-6 pls. A-G, pls. $1-76$, pls. A-F.

STEINDACHNER, $F$.

1874 - Die Süsswasserfische des südostlichen Brasilien. Sitz. K. Akad. Wiss., Wien, 70 (1):499-538, 5 pls.

1875 - Die Süsswasserfische des südostlichen Brasilien (ii). Sitz. K. Akad. Wiss., Wien, 71(1):211-245, 6 pls.

1876 - Die Süsswasserfische des südostlichen Brasilien (III). Sitz. K. Akad. Wiss Wien, 74(1):559-694, 13 pls.

1879 - Zur Fisch-fauna des Magdalenen-Stromes. Denks. K. Akad. Wiss., Wien, 39(1):19-78, 15 pls.
1880 - Zur Fisch-fauna des Cauca und der Flüsse bei Guayaquil. Denks, K. Akad. Wiss., Wien, 42:55-104, 9 pls.

WeITZMAN, S.H.

1977 - Hyphessobrycon socolofi, a new species of characoid fish (Teleostei: Characidae) from the rio Negro of Brazil. Proc. Biol. Soc. Washington, 90(2):348-357.

1978 - Three new species of fishes of the genus Nannostomus from the Brazilian states of Pará and Amazonas (Teleostei: Lebiasinidae). Smithsonian Contr. Zool., 263:1-14.

WeITZMAN, S.H. \& FINK, W.L,

No prelo - Interrelationships of the neon tetras, a unique group of South American characids (Pisces), with comments on the interpretation of the phylogeny of new world characoid fishes. Smithsonian Contr. Zool.

Wetrzman, S.H. \& Kanazawa, R.H.

1976 - Ammocryptocharax elegans, a new genus and species of riffle-inhabiting characoid fish (Teleostei: Characidae) from South America. Proc. Biol. Soc. Washington, 89(26):325-346.

1977 - A new species of pigmy characoid fish from the rio Negro and rio Amazonas, South America (Teleostei: Characidae). Proc. Biol. Soc. Washington, 90(1) : 149-160.

1978 - The South American fish genus Elacho. charax Myers with a description of a new species (Teleostei: Characidae). Proc. Biol. Soc. Washington, 91(1): 158-183.

(Aceito para publicação em 23/10/78) 